\title{
A Teoria da Argumentação na Língua no ensino de compreensão leitora: uma possibilidade de transposição didática
}

\section{The Language Argumentation Theory in reading comprehension teaching: a possibility of didactic transposition}

\author{
Luciana Idiarte Soares Falkenbach \\ Centro Universitário da Serra Gaúcha. Caxias do Sul, RS, Brasil.
Instituto de Desenvolvimento Educacional do Alto-Uruguai. Getúlio Vargas, RS, Brasil \\ Tânia Maris de Azevedo² \\ Universidade de Caxias do Sul, Programa de Pós-Graduação em Educação. Caxias do Sul, RS, Brasil.
}

Mestra em Educação pela Universidade de Caxias do Sul. Professora no Instituto de Desenvolvimento do Alto-Uruguai-Faculdades IDEAU e na Faculdade da Serra Gaúcha. (D) https://orcid. org/0000-0001-7554-2507 Email: luciana.isoares@hotmail.com

Doutora em Letras - Linguística Aplicada. Professora pesquisadora no Programa Doutorado Programa de Pós-Graduação em Educação da Universidade de Caxias do Sul. (i)https://orcid.org/0000-0002-0499-356X E-mail: tmazeved@ucs.br
RESUMO: Este estudo teve como principal objetivo a elaboração de uma proposta de transposição didática de alguns conceitos da Teoria da Argumentação na Língua, de Oswald Ducrot, Jean-Claude Anscombre e Marion Carel, com vistas a fornecer subsídios para que estudantes do Ensino Superior aperfeiçoem o desenvolvimento das habilidades de compreensão leitora dos articuladores mas e embora. Partimos da hipótese de que um número significante de universitários ainda precisa aprimorar suas habilidades linguístico-discursivas, para serem proficientes no uso do código escrito, suporte no alcance de seus objetivos de vida. A linguística saussuriana e a Teoria da Argumentação na Língua forneceram subsídios para a descrição semântica dos articuladores mas e embora. Os estudos sobre transposição didática, de Chevallard e Álvarez, foram redimensionados para a proposta de transformação didática, elaborada por Azevedo, visto que a aprendizagem de uma língua pressupõe o desenvolvimento de habilidades e não a formação de conceitos. Acreditamos que a partir desta proposta, novos direcionamentos metodológicos poderão ser pensados em relação ao desenvolvimento das habilidades pressupostas pela compreensão em leitura em diferentes níveis de ensino.

Palavras-chave: Educação; Aprendizagem de língua; Compreensão leitora; Semântica Argumentativa; Transposição e transformação didática.

ABSTRACT: The primary purpose of this study was to develop a proposal for the didactic transposition of some concepts from the Language Argumentation Theory, by Oswald Ducrot, Jean-Claude Anscombre and Marion Carel, in order to provide undergraduate students with resources to improve their reading comprehension skills of the articulators but and although. The fact that a significant number of students still need to master their linguistic and discursive abilities so as to be proficient in written language usage, support to life goals achievements, was assumption of the research. Saussure's linguistics and the Language Argumentation Theory based the semantic description of the articulators but and although. The studies on didactic transposition, by Chevallard e Álvarez, were revised for the proposal of the didactic transformation, developed by Azevedo, since language learning implies the development of abilities and not concept formation. I reckon that, from this investigation, new methodological directions might be thought towards the development of abilities implied in reading comprehension in all educational levels.

Keywords: Education. Language learning. Reading comprehension. Argumentative Semantics. Didactic transposition and transformation. 


\section{Introdução}

$\mathrm{s}$ defasagens em relação às habilidades linguístico-discursivas dos estudantes brasileiros de todos os níveis de ensino vêm sendo constatadas por avaliações externas, professores e até mesmo pela população em geral. Sobretudo, no cenário atual, no qual esses estudantes são inundados por uma avalanche de informações que necessitam ser selecionadas para que possam ser transformadas em conhecimentos, o fato de ingressarem no Ensino Superior com as mesmas carências é fator de grande preocupação.

É consenso que uma parte significativa dos universitários ainda precisa aprimorar suas habilidades de compreensão leitora, no intuito de que faça uso do discurso escrito, não apenas para o desempenho acadêmico mas também para as práticas sociais do dia a dia. Como decorrência dessa premissa, o problema da pesquisa que norteou a elaboração deste estudo assumiu a seguinte formulação: que elementos/aspectos/operações fundamentam uma proposta de transposição (transformação) didática da Teoria da Argumentação na Língua, de Oswald Ducrot, Jean-Claude Anscombre e Marion Carel, mais especificamente no que diz respeito à significação dos articuladores mas e embora, a fim de auxiliar estudantes do Ensino Superior a qualificarem o desenvolvimento da habilidade de compreensão do discurso escrito?

Por meio desta pesquisa, buscamos contribuir para a reflexão sobre como uma teoria linguística pode servir de base para a elaboração de material didático que vise ao aprimoramento de habilidades de compreensão leitora. Como pressuposto deste trabalho, entendemos que a aprendizagem de uma língua implica o desenvolvimento de habilidades de uso oral e escrito dessa língua, e não somente o estudo da metalinguagem. Portanto, os estudantes terão maiores chances de aprender a utilizar a língua escrita de modo adequado e eficaz à medida que essa se torne objeto de uso em situações enunciativas de leitura e produção discursiva, sendo que a função essencial do professor, como mediador de tal aprendizagem, vincula-se à organização de uma intervenção pedagógica problematizadora.

\section{Concepções de base: Teoria da Argumentação na Língua}

A Semântica Argumentativa foi desenvolvida primeiramente (no final da década de 60 do século XX) por Oswald Ducrot e Jean-Claude Anscombre e, a partir dos anos 90 do mesmo século, por Oswald Ducrot e Marion Carel. Assim, ela é estabelecida por esses teóricos por meio da Teoria da Argumentação na Língua (TAL).

O princípio fundamental da TAL, que permanece inalterado ao longo das diversas versões da Teoria, é o de que a argumentação está na língua. Explicando melhor esse pressuposto, a significação é constituída na língua, ou seja, "no próprio sistema linguístico que rege toda a produção linguageira" (AZEVEDO, 2006, p. 131). São as relações argumentativas que as entidades constituintes desse sistema mantêm umas com as outras que possibilitam a descrição da significação, e, consequentemente, as instruções necessárias para a constituição do sentido dos enunciados.

Após algumas diferentes versões, atualmente a TAL é composta pela Teoria da Polifonia ${ }^{1}$ que descreve a colocação de um conteúdo em discurso, "conteúdo, aqui, como a ideia, a informação, o tema objeto de um discurso, veiculado por ele" (AZEVEDO, 2014, p. 249) e a Teoria dos Blocos Semânticos, "cujo objeto de estudo é o conteúdo do discurso" (AZEVEDO, 2014, p. 249 grifo meu), em que o sentido é construído pela totalidade dos sentidos dos segmentos que constituem o encadeamento argumentativo.

${ }^{1}$ Utilizarei nesta pesquisa a versão da Teoria da Polifonia presente nas obras $O$ dizer e o dito (1987) e Polifonia y argumentación - conferencias del seminario Teoría de la Argumentación y Análisis del Discurso (1990). 


\subsection{Articuladores mas e embora de acordo com a TAL}

As noções de conector e articulador aparecem em diferentes obras e fases da TAL. Para Ducrot (2002), esses conceitos, juntamente com os modificadores (por exemplo, pouco, um pouco e muito) e os internalizadores (por exemplo, os empregos de em vão e alguns empregos de demais), fazem parte de uma categoria denominada palavras instrumentais ou palavras gramaticais. A principal característica desse tipo de palavra é que seu valor semântico se determina em relação a discursos que não são propriamente ligados a elas, isto é, "não designam nenhum 'elemento da realidade' (nem indivíduo, nem ação, nem estado, nem propriedade).” (DUCROT, 2002, p. 10 - grifo do autor). A elas estão contrapostas as palavras plenas, cuja característica é possuir conteúdo e, por isso, poderem ser descritas semanticamente. Vocábulos como prudente, medo e resolver são exemplos de palavras plenas.

Conectores e articuladores são diferentes na obra de Ducrot, pois, para o semanticista, os conectores (DONC e POURTANT) são entidades teóricas (no sentido de ser uma representação dos elementos que conectam) e têm a função de ligar dois segmentos, constituindo o encadeamento argumentativo ${ }^{2}$.

Já os articuladores são entidades lexicais (no sentido de uma palavra ou expressão atualizada no discurso/enunciado), tais como mas e seus equivalentes porém, entretanto, todavia e possuem a função de "comparar as argumentações que constituem o sentido dos segmentos que os precedem e os seguem." (DUCROT, 2002, p. 11).

${ }^{2}$ A função de um conector, pela TBS, é a de construir esses encadeamentos argumentativos, que podem ser de dois tipos: (a) normativo, composto pelos conectores do tipo de DONC (DC) com ou sem a negaço; e (b)transgressivo, composto pelos conectores do tipo de POURTANT (PT) cocrescidc não de no; e (b) transgressivo, composto pelos conectores do tipo de POURTANT (PT) acrescido ou não de negaça.o. Ducrot e Care utivalente em portugues se termos DONC e POURTANT e suas abreviaturas serão mantidos em francês nesta pesquisa.
Para uma melhor compreensão do que a TAL entende por conector e articulador, analisemos o discurso (D1) abaixo:

(D1) Está chovendo, mas vou passear

O discurso acima possui dois enunciados:

(1) está chovendo, portanto ficarei em casa em que se tem o encadeamento argumentativo normativo (representado pelo conector DONC) chover DC ficar em casa; e

(2) está chovendo, no entanto vou passear

em que se tem o encadeamento argumentativo transgressivo (representado pelo conector POURTANT) chover PT passear.

Esses dois enunciados são relacionados pelo articulador mas, que tem a função de apresentar a recusa de que o mau tempo possa atrapalhar o passeio. Tem-se então um esquema como o seguinte:

\begin{tabular}{c|c|c} 
X CONECTOR $\mathrm{Y}^{\prime}$ & ARTICULADOR & $\mathrm{X}$ CONECTOR' $\mathrm{Y}^{\prime}$ \\
chover DC ficar em casa & MAS & chover PT passear
\end{tabular}

Em relação ao articulador mas, Ducrot (1989) aponta que o tipo de sequência " $X$ mas $Y$ "3 implica que $\mathrm{X}$ veicula um conteúdo dirigido para uma certa conclusão. No exemplo acima: está chovendo $\rightarrow$ a chuva atrapalha o passeio $\rightarrow$ então, não vou passear. Já Y veicula um conteúdo dirigido para a conclusão inversa, no mesmo exemplo, a conclusão é vou passear, posição

${ }^{3}$ Nessa obra, Ducrot utiliza $p$ mas $q$, sendo que as letras $p$ e $q$ referem-se a proposições. Para facilitar a compreensão, optei pela padronização, utilizando o formato $X$ mas $Y$, também utilizado por Ducrot em outros textos. 
que o locutor assume no discurso por ele sustentado, a partir de Y e não de $\mathrm{X}$. Por essa razão, o encadeamento argumentativo dos discursos formados por " $X$ mas $Y$ " coincide com o encadeamento argumentativo do enunciado E(2) nesse caso, chover PT passear.

Na obra Polifonia y Argumentacíon (1990), encontra-se o estudo mais extenso realizado por Ducrot sobre o articulador mas. Lá, o linguista propõe uma forma de encontrar a significação da estrutura " $X$ pero $Y$ ", ou em português, " $X$ mas $Y$ ", constituída pelo conjunto de referências que a estrutura fornece a quem interpreta os discursos. Assim, para alcançar-se a significação, podem ser cumpridas as seguintes instruções:

construa quatro enunciadores. $\mathrm{O}$ enunciador E1 contém o ponto de vista de $\mathrm{X}$, o enunciador E2 tira uma conclusão $r$ a partir de $\mathrm{X}$, conclusão que precisa ser descoberta (quando queremos interpretar o enunciado é necessário inventar essa $r$ ). 0 enunciador E3 sustenta o ponto de vista de Y e, a partir de Y, o enunciador E4 conclui não $r$. (DUCROT, 1988, p. 71 Tradução minha). ${ }^{4}$

Ao aplicarmos essas instruções ao discurso (D1) Está chovendo, mas vou passear, teremos os quatro enunciadores:

$\mathrm{E}_{1}$ : está chovendo - contém o ponto de vista de X;

$\mathrm{E}_{2}$ : não vou passear - tira uma conclusão a partir de $\mathrm{X}$;

$\mathrm{E}_{3}$ : a chuva não é empecilho - sustenta a posição de $\mathrm{Y}$;

$\mathrm{E}_{4}$ : vou passear - conclui o inverso da conclusão do $\mathrm{E}_{2}$.

Após o estabelecimento dos quatro enunciadores, Ducrot (1990) afirma que é preciso encontrar as posições do locutor em relação a eles

\footnotetext{
${ }^{4}$ Tradução livre de: "construya cuatro enunciadores. El enunciador E1 contiene el punto de vista de X, el enunciador E2 saca una conclusión $r$ a partir de X, conclusión que hay de ser descoberta (cuando queremos interpretar el enunciado hay que inventar esa $r$ ). El enunciador $\mathrm{E} 3$ sostiene el punto de vista de Y y, a partir de Y, el enunciador E4 concluye no $r$."
}

para descrever a significação de um discurso com mas. O que se tem de comum nesse tipo de sequência ( $X$ mas $Y$ ) é o fato de o locutor recusar o $\mathrm{E}_{2}$ e assumir o $\mathrm{E}_{4}$, para concluir não $r$. Quanto ao $\mathrm{E}_{1} \mathrm{e}$ ao $\mathrm{E}_{3}$, o locutor não os nega, e simplesmente os aceita. No exemplo acima, o locutor aceita que está chovendo $\left(\mathrm{E}_{1}\right)$, recusa não ir passear $\left(\mathrm{E}_{2}\right)$, assume que vai passear $\left(\mathrm{E}_{4}\right)$, pois aceita que a chuva não é um empecilho $\left(\mathrm{E}_{3}\right)$.

Vogt (1989), em parceria com Ducrot, propõe uma explicação semântica para a utilização do articulador mas. Os semanticistas explicam que em algumas línguas de origem românica, esse morfema não é derivado do adversativo latino sed, mas do advérbio latino magis, uma das maneiras de formar o comparativo de superioridade.

Em muitas línguas, incluindo o português, quando o mas é utilizado como derivado do advérbio magis, ele admite duas funções: (a) a do espanhol sino e do alemão sondern, referida por SN; (b) a do espanhol pero e do alemão aber, referida por PA.

A função do mas SN pode ser explicada da seguinte forma: o mas SN serve para retificar uma proposição e vem sempre depois de uma negação. Um exemplo dessa função pode ser: Sandra não é velha, mas madura. Aqui, mas retifica a informação provida pelo adjetivo velha e a substitui por madura, isto é, coloca madura no lugar de velha. Assim, o mas SN faz parte de uma construção sintática na qual a primeira proposição (A) é negativa, Sandra não é velha; e a segunda (B), afirmativa, Sandra é madura, apresentando-se como a mais adequada. $\mathrm{O}$ articulador mas ligase a $\mathrm{B}$ (não $A$, mas $B$ ), pois esse é o ponto de vista assumido. Aqui, o valor semântico da negação gramatical precisa ser entendido como uma forma especificamente forte de negação argumentativa, já que mesmo que algo seja negado, seu sentido será mantido. Dito de outro modo, no momento em que se nega A, o locutor retifica essa enunciação (VOGT; DUCROT, 1989; TOLDO, 2002). 
O mas PA tem como função introduzir uma proposição que orienta para uma conclusão não $r$, diferente da conclusão $r$ a que A poderia conduzir. Para ilustrar essa explicação, apresentamos o discurso (D2):

(D2) Ele já é rico, mas ainda trabalha muito

Nesse discurso, o primeiro enunciado (1)

(1) ele é rico

orienta para uma conclusão $r$, a de que ele não precisaria mais trabalhar tanto. O mas PA vai justamente inverter essa orientação, e isso é visível pelo que está atualizado no (2)

(2) mas ainda trabalha muito

Resumindo, o mas PA apresenta dois segmentos que autorizam conclusões inversas. Além disso, é possível perceber que a posição enfatizada pelo locutor é a do (E2), ou seja, o locutor identifica-se com (E2).

Visto que o articulador embora é objeto de análise deste estudo tanto quanto o mas, apresentaremos uma descrição do embora tendo por base as concepções construídas por Ducrot para o articulador mas. Reconhecemos que, de acordo com a sintaxe, mas e embora são classificados de maneira diferente, conforme as relações construídas entre duas orações: mas como uma relação coordenativa adversativa e embora como uma relação subordinativa concessiva. Salientamos que a aproximação que realizamos entre eles neste trabalho pode ser possível, já que o critério utilizado é semântico, e, assim, baseamo-nos na concepção de que ambos trazem a ideia de oposição. Essa noção fica evidente no momento em que realizamos a comparação entre discursos (D3) e (D4) contendo os dois articuladores. Vejamos:

(D3) Era um homem rico, mas preferia as coisas simples da vida
(D4) Embora fosse um homem rico, preferia as coisas simples da vida

Os dois discursos acima são compostos pelo enunciado

(1) um homem era rico

e pelo enunciado

(2) um homem apreciava as coisas simples da vida

articulados em (D3) por mas e em (D4) por embora, compondo o encadeamento argumentativo riqueza PT simplicidade.

$\mathrm{Na}$ comparação com as funções do mas (PA ou SN), abordadas por Ducrot e Vogt (1989), a função do embora aproxima-se do que os autores denominam mas PA, pois recordamos que os discursos que apresentam o mas SN mostram uma proposição retificada por outra proposição. Esse não é o caso do embora, que, assim como o mas PA, introduz uma proposição orientadora para uma conclusão não $r$, oposta a uma conclusão $r$ para a qual a proposição inicial poderia conduzir. Portanto, observando-se o discurso abaixo (D5) com embora:

(D5) Embora a tarefa seja difícil, estou disposto a concluí-la nota-se a composição por dois enunciados

(1) a tarefa é difícil

em que se tem o encadeamento argumentativo normativo (representado pelo conector DONC) dificuldade DC desistência da tarefa e

(2) estou disposto a concluir a tarefa

${ }^{5}$ Na língua portuguesa, admite-se também a construção Preferia as coisas simples da vida, embora fosse rico. Como a posição do articulador embora não tem implicação no sentido constituído por ele no discurso, pensamos não ser necessário trabalhar com exemplos que deem conta de tal construção. 
em que se tem o encadeamento argumentativo transgressivo (representado pelo conector POURTANT) dificuldade PT conclusão da tarefa.

Esses dois enunciados são articulados pelo embora, que tem a função de apresentar a recusa ao fato de a dificuldade da tarefa impedir sua conclusão (semelhante à função do mas PA), em um encadeamento argumentativo que coincide com o encadeamento argumentativo do enunciado (2): dificuldade PT conclusão da tarefa. Desse modo, o mesmo discurso poderia ter sido atualizado utilizando o articulador mas

(D6) A tarefa é difícil, mas estou disposto a concluí-la

No discurso acima (D6), articulado por mas, são realizados os mesmos encadeamentos argumentativos do discurso (D5), composto por embora. São eles: dificuldade DC desistência da tarefa e dificuldade PT conclusão da tarefa.

Retomamos aqui as instruções apresentadas por Ducrot (1990) para a análise polifônica de mas:

1. construir quatro enunciadores;

2. o enunciador $\mathrm{E}_{1}$ contém o ponto de vista de $\mathrm{X}$;

3. o enunciador $E_{2}$ tira uma conclusão $r$ a partir de $X$, conclusão que haverá de ser descoberta;

4. o enunciador $\mathrm{E}_{3}$ sustenta o ponto de vista de $\mathrm{Y}$ e, a partir de $\mathrm{Y}$;

5. o enunciador $\mathrm{E}_{4}$ conclui não $r$.

Ao aplicá-las ao discurso (D5) Embora a tarefa seja difícil, estou disposto a concluí-la, temos

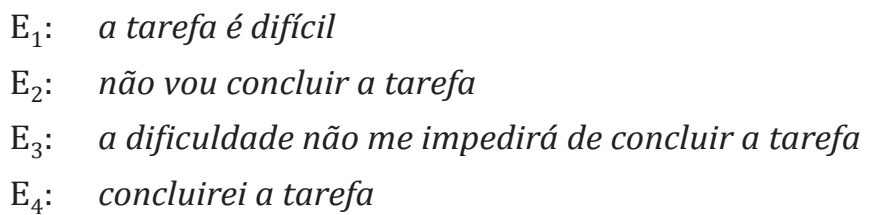

A segunda tarefa proposta por Ducrot (1990) para quem interpreta um discurso com mas é encontrar as posições do locutor em relação aos quatro enunciadores construídos. Conforme o linguista, nesse tipo de enunciado

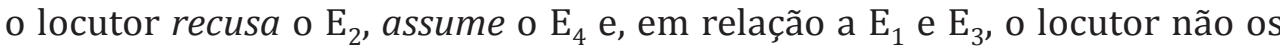
recusa, somente os aceita.

Ao aplicar as mesmas instruções à leitura polifônica do embora temos: o locutor aceita que a tarefa é difícil $\left(\mathrm{E}_{1}\right)$, recusa a não realização da tarefa $\left(\mathrm{E}_{2}\right)$, aceita que a dificuldade não o impedirá $\left(\mathrm{E}_{3}\right)$, pois assume o fato de que vai concluir a tarefa $\left(\mathrm{E}_{4}\right)$.

Neste ponto, cabe utilizar a explicação semântica para a relação concessiva proporcionada pela atualização do articulador embora no discurso. Pode-se dizer que, pelos enunciadores $E_{1}$ e $E_{2}$, o locutor (L1) pressupõe a presença de outro possível locutor (L2) e a ele concede voz, sendo $E_{1}$ e $E_{2}$ os pontos de vista que esse locutor pressuposto (L2) assumiria. Analisando o discurso (D5), isso quer dizer que o locutor (L1) aceita que, com base no $\mathrm{E}_{1}$ a tarefa é difícil, o (L2) poderia concluir $\mathrm{E}_{2}$ não vou concluir a tarefa. Entretanto, refuta essa conclusão, ao aceitar $\mathrm{E}_{3}$ a dificuldade não me impedirá e assumir $\mathrm{E}_{4}$ : concluirei a tarefa.

Em caráter de cogitação, visto que uma afirmação mais contundente demandaria uma investigação mais profunda e ampliada, pode-se pensar que a diferença semântica existente entre os discursos atualizados com o mas e os com embora é a consideração de um locutor pressuposto que o uso do embora proporciona.

Para comparação, recuperemos os discursos (D5) e (D6):

(D5) Embora a tarefa seja difícil, estou disposto a concluí-la

(D6) A tarefa é difícil, mas estou disposto a concluí-la

É possível cogitar que no discurso (D6) os quatro pontos de vista pertencem ao locutor (L1), e ele próprio tem as atitudes de aceitar $\mathrm{E}_{1}$ a tarefa é 
difícil e $\mathrm{E}_{3}$ a dificuldade não me impedirá, recusar $\mathrm{E}_{2}$ não vou concluir a tarefa e assumir $\mathrm{E}_{4}$ concluirei a tarefa. Entretanto, no discurso (D5), o locutor (L1) aceita $E_{1}$ e concede voz a outro locutor (L2) que, ao também aceitar $E_{1}$, conclui $\mathrm{E}_{2}$. Assim, o locutor (L1) "retomaria" sua voz nos enunciadores $\mathrm{E}_{3}$ e $\mathrm{E}_{4}$.

Ao concluir as considerações acerca de como a TAL pode contribuir para a compreensão de discursos escritos articulados por mas e embora, acreditamos ser pertinente salientar que teremos por base para a elaboração da transposição didática a seguir a concepção de que os articuladores mas e embora possam ser aproximados, sendo passíveis da mesma transposição, uma vez que, semanticamente, ambos possibilitam construções por oposição, em que existe o rompimento de uma expectativa, possibilitada pelo sistema linguístico ou pelo processo enunciativo.

\section{Proposta de transposição (transformação) didática de alguns conceitos da Teoria da Argumentação na Língua}

O termo transposição didática (TD) é oriundo da sociologia, sendo introduzido por Verret, em 1974, e, mais adiante, desenvolvido no campo da matemática por Yves Chevallard. Esse conceito é de grande importância tanto para a pesquisa quanto para a formação de professores e também contribuiu muito para a consideração do campo da didática como uma disciplina científica além dos diversos componentes curriculares (matemática, ciências, línguas, etc.) (ÁLVAREZ, 2005).

O processo de transposição didática é constituído nas adaptações pelas quais um objeto do saber passa para tornar-se objeto de ensino no ambiente escolar. Tais adaptações incluem desde as que dizem respeito a sua ordem científica e aos processos de construção, até as modificações pelas quais o discurso científico passa para ser difundido e, finalmente, alcançar os estudantes. Transpor didaticamente é definir e analisar a passagem dos saberes sábios ${ }^{6}$, ou seja, dos conhecimentos científicos e técnicos, ou das disciplinas de referência, aos saberes a serem ensinados (ÁLVAREZ, 2005; CHEVALLARD, 2005) em instâncias pedagógicas.

Durante a passagem do conhecimento produzido pelos cientistas para o conhecimento realmente necessário para os educandos, nessa espécie de processo de adaptação, cabe ao professor recordar que o saber sábio se origina no propósito dos estudiosos de tentar encontrar respostas para os problemas da realidade. Os resultados e as conclusões encontrados nesses estudos são divulgados em textos teóricos e científicos que geralmente são de difícil acesso ao público leigo pelo nível de abstração que trazem. Dessa forma, fica clara a importância de um trabalho de transposição didática para que esses conteúdos realmente se tornem objetos do saber a ser ensinado (CHEVALLARD, 2005).

A falta das ações de seleção, adaptação e simplificação dos conhecimentos, nas quais as condições de aprendizagem dos educandos sejam consideradas no intuito de que a aprendizagem se desenvolva poderá ocasionar distorções no processo pedagógico. Um exemplo desse tipo de situação são os conceitos da gramática normativa (conhecimento científico, saber sábio) inadequadamente transferidos para o ambiente da sala de aula, em grande parte, no ingênuo intuito de que os alunos desenvolvam habilidades relacionadas à leitura e a escrita. Uma vez que o domínio de uma habilidade, de um saber-fazer, requer a prática no seu uso, seria improvável que por meio de atividades de nomeação e classificação de itens morfológicos e sintáticos os estudantes alcançassem a proficiência linguístico-discursiva.

A esse respeito, Azevedo (2016a) afirma que diferentemente de disciplinas curriculares tais como História, Geografia, Biologia e Química,

${ }^{6}$ Saberes sábios e saberes a serem ensinados são termos cunhados por Chevallard (2005) 
a aprendizagem de língua, seja ela materna ou estrangeira, demanda o desenvolvimento de habilidades, e não a formação de conceitos. A autora até mesmo afirma que pouco adianta a formação de conceitos como língua, frase, verbo, advérbio para a aprendizagem do uso da língua em sua forma oral e escrita. Por essa razão, o que propomos a seguir, com base em Azevedo (2016), é uma revisão do conceito de transposição didática para o de transformação didática.

\section{Transformação didática no ensino de língua}

Em favor da revisão (ou mesmo expansão) do conceito de transposição didática para o ensino e aprendizagem de língua, está o argumento de que nesses processos o objetivo maior é o de desenvolvimento de habilidades ${ }^{7}$ linguageiras e não a formação de conceitos, consequentemente, os "conteúdos" a ensinar não poderiam ser reduzidos a saberes científicos transpostos, mas precisam ser transformados com vistas a contribuir para a utilização eficaz da língua; e isso quer dizer de modo adequado e apropriado, em conformidade com o(s) propósito(s) e o(s) interlocutor(es) do usuário em cada situação enunciativa (AZEVEDO, 2016a; PETITJEAN, 2008). Mais ainda, cabe destacar a dupla função que a língua possui, pois, ao mesmo tempo em que é ferramenta de interlocução para a aprendizagem dos saberes, ela própria é também objeto de aprendizagem e ensino.

Considerando a particularidade do componente curricular de Língua Portuguesa em relação aos demais componentes curriculares, conforme Azevedo (2016a, p. 77), a revisão do conceito de transposição didática passa pela consideração do cenário da pesquisa e do ensino, pois, "no caso das teorias linguísticas aplicadas ao ensino de língua, há duas dimensões a serem especificadas: as da formação de professores de língua e a do ensino

7 Repetimos que neste trabalho entendemos habilidade como um saber fazer. de língua na Educação Básica". O objetivo didático da aplicação das teorias linguísticas caracteriza a especificidade de cada dimensão.

Na dimensão do ensino e da aprendizagem de língua na Educação Básica, uma teoria linguística tem como finalidade "transformar-se didaticamente em uma espécie de 'ferramenta' que potencialize, por meio de atividades (problemas e exercícios), o desenvolvimento das habilidades indispensáveis a essa aprendizagem." (AZEVEDO, 2016a, p. 77 - grifo da autora).

É na perspectiva de que a TAL pode servir de recurso para o desenvolvimento de habilidades linguísticas, que apresentamos a proposta de transformar a Teoria em uma ferramenta didática, com o intuito de possibilitar que estudantes do ensino superior possam compreender o uso dos articuladores mas e embora no discurso escrito. As figuras a seguir têm o propósito de tornar sinteticamente visíveis para o leitor as etapas da transformação didática.

\section{Teoria da Argumentação na Língua no ensino da compreensão dos articuladores mas e embora presentes no discurso escrito}

O desafio de propor a transformação didática de alguns pressupostos da Teoria da Argumentação na Língua, a fim de que ela torne-se recurso didático-metodológico será cumprido aqui em caráter de delineamento inicial. Portanto, sua testagem e validação serão objeto de estudo de posteriores investigações.

Apresentaremos a seguir propostas de atividades voltadas à compreensão dos articuladores mas e embora, com apoio em concepções da TAL ${ }^{8}$. Ao fim, apontamos os procedimentos teórico-metodológicos utilizados por nós na

8 Oriundas da Teoria da Polifonia e da Teoria dos Blocos Semânticos. 
transformação didática da noção de articulador com vistas à aprendizagem desse processo de semântica.

Retomando as instruções de Ducrot para a descrição de discursos com o articulador mas, recordamos que, para o teórico, na sequência $X$ mas $Y$ sempre existem quatro enunciadores, quatro pontos de vista apresentados pelo locutor. Além disso, o semanticista mostra que, em relação a esses pontos de vista, o locutor toma posições: assume, aceita ou recusa cada um dos enunciadores por ele mobilizados. É essa perspectiva que fundamenta a atividade ${ }^{9}$ que propomos a seguir.

\section{ATIVIDAde 1}

Você aprendeu que, nos enunciados articulados pelo mas, tais como $A$ casa é pequena, mas todos se sentem confortáveis, o primeiro segmento, a casa é pequena, apresenta um ponto de vista que orienta para uma conclusão, no exemplo, a de que as pessoas não se sentiriam confortáveis. Já o segundo segmento, todos se sentem confortáveis, mostra um ponto de vista inverso à conclusão propiciada pelo primeiro segmento. No exercício que segue, você terá que construir enunciados articulando as duas informações dadas por meio do mas, e mantendo a mesma relação apresentada nos exemplos.

Informações A: cansaço - felicidade

Podia perceber que ela estava cansada, mas feliz por ver seus filhos saudáveis.

Informações B: trabalho - sucesso

Informações C: palestra interessante - aula monótona

Informações D: arrogância - medo

Informações E: férias - dinheiro

\footnotetext{
9 O discurso da atividade está presente em uma questão do ENADE 2012 (Exame Nacional de Desempenho dos Estudantes). Fiz essa escolha, pois o ENADE avalia o rendimento dos alunos dos cursos de graduação (público alvo desta transformação didática), ingressantes e concluintes, em relação aos conteúdos programáticos dos cursos em que estão matriculados.
}

Espera-se que os estudantes possam construir discursos semelhantes a (B) Maria trabalha pouco, mas é uma profissional de sucesso; (C) A palestra do escritor é interessante, mas sua aula é monótona; (D) Seu semblante demonstrava arrogância, mas, na verdade, ele sentia medo; e (E) Sara queria muito sair de férias, mas o dinheiro era escasso.

Após a construção dos discursos, é possível analisar juntamente com os estudantes, quais pontos de vista foram recusados pelo locutor de cada discurso. Se os exemplos acima fossem utilizados para a análise, os pontos de vista recusados seriam:
(B) Maria não é uma profissional de sucesso;
(C) a aula do escritor é interessante;
(D) ele não sentia medo; $\mathrm{e}$
(E) Sara tinha dinheiro.

Após a exposição da proposta de transformação didática da TAL para a compreensão do articulador mas, apresentamos agora nosso entendimento sobre como a mesma Teoria pode auxiliar estudantes do Ensino Superior a compreender os discursos escritos articulados pelo embora.

Recordamos a aproximação que fizemos entre os articuladores mas e embora, em que utilizamos as mesmas instruções fornecidas por Ducrot para a descrição polifônica dos discursos articulados por mas para a compreensão de discursos articulados por embora.

\section{ATIVidade 2a}

O enunciado abaixo faz parte de uma reportagem sobre a exportação de carne pela Austrália.

Embora as exportações para a Indonésia em fevereiro tenham declinado em 23\% com relação ao ano anterior, permaneceram acima dos níveis esperados. 
Conforme vimos em nossas aulas, o locutor é o responsável pelo que está sendo dito, adotando, portanto, diferentes atitudes em relação a cada ponto de vista expresso no que ele diz. Sendo assim, o locutor pode aceitar, recusar ou assumir cada um desses pontos de vista. O locutor usa na construção do enunciado anteriormente apresentado quatro pontos de vista.

Analise e relacione os pontos de vista do locutor às suas atitudes:

\begin{tabular}{|l|l|}
\hline ATITUDES & PONTOS DE VISTA \\
\hline & $\begin{array}{l}\text { ( ) } \mathbf{P V}_{\mathbf{1}} \text { : as exportações para a Indonésia em fevereiro declinaram em } 23 \% \text { com } \\
\text { relaço ao ano anterior }\end{array}$ \\
\hline (a) aceita & ( ) $\mathbf{P V}_{2}$ : as exportações para a Indonésia permaneceram abaixo dos níveis esperados \\
\hline (b) recusa & ( ) $\mathbf{P V}_{3}$ : o declínio das exportações para a Indonésia não foi maior do que se esperava \\
\hline (c) assume & ( ) $\mathbf{P V}_{4}$ : as exportações para a Indonésia permaneceram acima dos níveis esperados \\
\hline
\end{tabular}

A continuação dessa atividade tem por objetivo proporcionar que os estudantes percebam a diferença semântica existente entre discursos articulados por mas e por embora. Portanto, a atividade subsequente seria:

\section{ATIVidade 2b}

Ainda de acordo com o que estudamos, os enunciados articulados por mas e embora sempre apresentam um ponto de vista que é recusado pelo locutor. A diferença entre eles é que, com o mas, o próprio locutor adota atitudes (de aceitar, recusar ou assumir) em relação a cada ponto de vista; já com o embora, é como se o locutor desse voz a outro possível locutor, outra pessoa do discurso que adotaria atitudes (de aceitar, recusar ou assumir) em relação aos pontos de vista. Dos pontos de vista do enunciado em análise, dois foram adotados por esse outro locutor. Assinale-os:
( ) $\quad \mathbf{P V}_{\mathbf{1}}$ : as exportações para a Indonésia em fevereiro declinaram em $23 \%$ com relação ao ano anterior

( ) $\mathbf{P V}_{2}$ : as exportações para a Indonésia permaneceram abaixo dos níveis esperados

( ) $\mathbf{P V}_{3}$ : o declínio das exportações para a Indonésia não foi maior do que se esperava

( ) $\mathbf{P V}_{\mathbf{4}}$ : as exportações para a Indonésia permaneceram acima dos níveis esperados

A próxima atividade envolvendo a compreensão do articulador embora tem por fundamentação os conceitos de encadeamento argumentativo e bloco semântico, de modo semelhante à atividade 2. Nela, a partir dos blocos semânticos apresentados, os estudantes precisarão construir discursos articulados por embora.

Dados os exemplos de atividades originadas da transformação didática da Teoria da Argumentação na Língua, indicamos os procedimentos teóricometodológicos norteadores desse processo.

Procedimento 1 - compreensão aprofundada dos fundamentos da TAL para que as ações de seleção, transformação e simplificação dos conceitos relevantes para o ensino de língua pudessem ocorrer.

Procedimento 2 - entendimento de que a aprendizagem de língua materna no contexto educacional pressupõe o desenvolvimento de habilidades e não a formação de conceitos, por essa razão, as atividades propostas não poderiam ser reduzidas aos saberes científicos (aqueles oriundos da TAL) transpostos, mas sim que o conhecimento científico precisaria ser transformado em um "instrumento" para os aprendizes apropriarem-se e utilizarem os mecanismos de constituição de sentido que a língua dispõe.

Procedimento 3 - noção de que as atividades/exercícios precisavam ser organizadas de modo problematizador e desafiador, possibilitando ao estudante o uso efetivo das possibilidades de construção de sentido da língua. 
- Procedimento 4 - percepção de que o discurso científico, na maior parte das vezes hermético e denso, precisa passar por um processo de adaptação em termos de formulação linguística com a finalidade de ser compreendido pelos aprendizes.

Reafirmamos que as atividades que apresentamos aqui são somente um esboço de como a TAL, com suas versões da Teoria da Polifonia e da Teoria dos Blocos Semânticos, pode ser transformada didaticamente para promover o desenvolvimento da compreensão do sentido manifesto pelos articuladores mas e embora. Ainda assim, surgem como uma possibilidade do uso de conceitos teóricos como instrumento mediador para o ensino de língua numa perspectiva semântica, visto que uma provável causa para as dificuldades de compreensão é a falta de reconhecimento pelos leitores de itens lexicais reveladores da organização da informação e relevantes para o conjunto do conteúdo escrito, por exemplo, os articuladores.

Pode-se conjecturar que o maior avanço possibilitado pela transformação didática da TAL que apresentamos neste estudo é a contribuição para o entendimento das relações evidenciadas pelos articuladores mas e embora no intuito maior de promover o rompimento das barreiras existentes entre o que está posto e pressuposto, e, consequentemente, para compreensão da constituição do sentido do discurso.

\section{Referências}

ALVAREZ, Teodoro. Didáctica del texto en la formación del professorado. Madri: Síntesis, 2005.

AZEVEDO, Tânia Maris de; ROWELL, Vania Morales. Uma proposta de língua materna instrumental para o Ensino Fundamental. In: CONGRESSO LATINO AMERICANO SOBRE FORMAÇÃO DE LÍNGUAS / ENCONTRO CATARINENSE DE FORMAÇÃO DE PROFESSORES DE LÍNGUAS, I., 2006, Florianópolis-SC. Anais do ... Florianópolis: UFCS, 2006. 1 CD.
AZEVEDO, Tânia Maris de. Em busca do sentido do discurso: a semântica argumentativa como uma possibilidade para a descrição do sentido do discurso. Caxias do Sul: EDUCS 2006.

AZEVEDO, Tânia Maris de. Transposição didática de gêneros discursivos: algumas reflexões. Desenredo, Passo Fundo, v. 6, n. 2, p. 198-214, jul./dez. 2010.

AZEVEDO, Tânia Maris de. 0 discurso didático: testagem de um modelo para descrição do sentido pela Semântica Argumentativa. Revista de Letras, Fortaleza, v. 1/2, n. 31, p. 72-82, jan./dez. 2012.

AZEVEDO, Tânia Maris de. Por uma aprendizagem significativa da língua materna: o ensino fundamentado em Saussure e Ausubel. Nonada Letras em Revista, Porto Alegre v. 1, n. 22, p. 192-212, 2013.

AZEVEDO, Tânia Maris de. Ler "vendo" vozes: a polifonia no discurso. Educação Unisinos. São Leopoldo, v. 18, n. 3, p. 249-257, set./dez. 2014.

AZEVEDO, Tânia Maris de. Polifonia linguística: uma proposta de transposição didática para o ensino da leitura. Letras de Hoje, Porto Alegre, v. 51, n.1, p. 73-81, jan./mar. 2016a.

AZEVEDO, Tânia Maris de. Encadeamentos argumentativos, relações sintagmáticas e associativas: reflexões sobre o ensino da leitura. Antares. Caxias do Sul, v. 8, n. 15, p. 48-65, jan./jun. 2016b.

CAREL, Marion; DUCROT, Oswald. Atualização da polifonia. Desenredo, Passo Fundo, v. 6 , n. 1, p. 9-21, jan./jun. 2010.

CHEVALLARD, Yves. La transposición didáctica: del saber sábio al saber enseñado. Buenos Aires: Aique Grupo, 2005.

DUCROT, Oswald. Les mots du discours. Paris: Minuit, 1980

DUCROT, Oswald. Provar e dizer: linguagem e lógica. São Paulo: Global, 1981.

DUCROT, Oswald. Enunciação. In: Enciclopédia EINAUDI: Linguagem - Enunciação. Lisboa: Imprensa Nacional-Casa da Moeda, 1984. v. 2, p. 368-393.

DUCROT, Oswald. O dizer e o dito. São Paulo: Pontes, 1987.

DUCROT, Oswald. Argumentação e "topoi" argumentativos. In: GUIMARÃES, Eduardo (Org.). História e sentido na linguagem. Campinas: Pontes, 1989.

DUCROT, Oswald; VOGT, Carlos. De magis a mas: uma hipótese semântica. In: VOGT, Carlos. Linguagem, pragmática e ideologia. São Paulo: HUCITEC, 1989. 
DUCROT, Oswald; VOGT, Carlos. Polifonia y argumentación - conferencias del seminario Teoría de la Argumentación y Análisis del Discurso. Cali, Universidad del Valle, 1990.

DUCROT, Oswald; VOGT, Carlos. Os internalizadores. Tradução de Leci Borges Barbisan. Letras de Hoje, Porto Alegre v. 37, n. 3, p. 7-26, 2002.

DUCROT, Oswald; VOGT, Carlos. Los bloques semânticos y el cuadrado argumentativo: conferencia 2. In: CAREL, Marion; DUCROT, Oswald. La semántica argumentativa: una introducción a la teoria de los bloques semânticos. Edição literária e tradução de María Marta G. Negroni e Alfredo M. Lescano. Buenos Aires: Colihue, 2005. p. 27-50.

FLORES, Valdir do Nascimento (Org.) et al. Dicionário de linguística da enunciação. São Paulo: Contexto, 2009.

PETITJEAN, André. Importância e limites da noção de transposição didática para o ensino do francês. Tradução de Ana Paula Guedes e Zélia Anita Viviani. Fórum Linguístico, v. 13, n. 1, p. 71-99, jan./jun. 2010.

SAUSSURE, Ferdinand de. Curso de lingüística geral. 27. ed. São Paulo: Cultrix, 2006.

SAUSSURE, Ferdinand de. Escritos de lingüística geral. (Editado por S. Bouquet e R. Engler). São Paulo: Cultrix, 2004.

TOLDO, Cláudia Stumpf. A relação entre palavra e imagem no texto publicitário: linguagens que argumentam. Letras de Hoje, Porto Alegre, v. 37, n. 3, p. 149-162, set. 2002.

Recebido: 20/07/2017

Aceito: 15/11/2017 